\title{
$20 \mathfrak{c} \in$
}

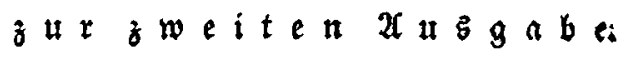

$\mathfrak{S}_{\text {ie }}$ Zufforberung meines biebern $\mathfrak{s}$ erten $\mathfrak{B}$ et: legers fu Bearbeitung einer jweiten Zlusgabe meines erften $\mathfrak{B e r f u d f s ~ i n ~ b e r ~ E d f r i f t f f e l l e r e i , ~}$ weldje idl als ben beften Beeweiz son ber allges meinen gứtigen Zlufnaḩme beffelben an「ef̧en muf́, ift mir ein neuer Sporn gewefen, folden bie

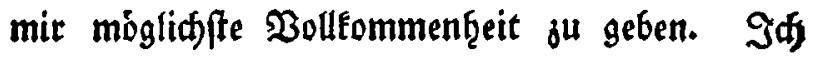
habe ou bem Enbe allen fleif angewanbt uns werbe mid auf alle Siseife bemúţen, mid bes Beifalls wứrbig zu madjen, ben meine Bemús haung, angeḩenden కanowirtţen ridttige Begriffe úber bie einjelnen Thęeile ber theoretif fifen Defonomie ju berffiffen unb fie in ben Stand ju feşen, lïf vor mandem Fef̧ler uns mandjen Sdjaben ju hุutten, gefunben ḩat. 
Bei meinem fortgeferten Stubium ber land, wirthidaft bin id) nod) auf mandje bisger uns benrbeitete Ţheile berfelben aufmerffam gewors Den uns bie ef̨renvolle 2 ufforberung, zur Heber. nef̧mung der Stelle eines offentlidjen. Sę̧rers biefer widltigen und vielumfaffenden Wiffenfaaft, Ģat mir beren $\mathfrak{B}$ carbeitung jut গyfitit gemadt.

Da nun berfobicoene meiner gưtigen Seertn

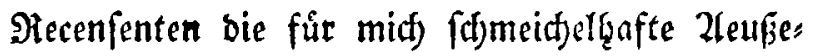
kung gemadjt ḩaben, Daßj meine aul Evfaḩrung

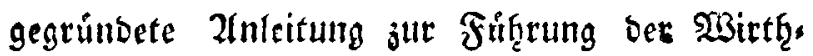

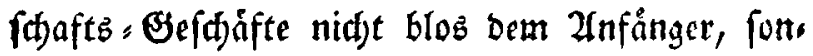
Dern audi) bem wirkliden Draktifer einigen $\mathfrak{N u}$, zen gewåf̨ren fónne, fo ḩat bieß̧ midh beroogen, Den Plan meines Berfs zu erweitern unb Darin alle bie widtigften Sheile ber Defunomie ju bes arbeiten. SBeldje idh bafúr f̧alte, wirb man in §. III. Des erften $\mathfrak{S}$ auptftúcées finten; worin idf) Den Begriff Der theoretifuen und praktifhen Defonomie feftjuftellen uno ben einer grůnolis

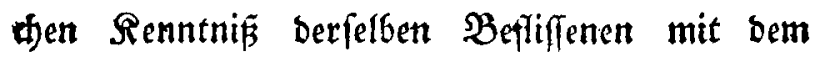
gangen llmange foines @tubiumb befannt jut madjen, iţa aud in ben Stano zu fegen ges

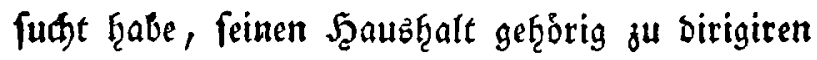
unb in allen Bweigen beffelben bie fo widtige uns notfige Dronung zu exhalten. Jđ slaube 
mir (ffmeidjeln ju durrfen, baß in Gierburd) bem Ganjen meţe $\mathfrak{B o l l f f a ́ n d i g f e i t ~ v e r ( d ) a f f t ~ u n o ~ d i e ~}$ Uleberfidjt bes Sjanjen zugleid) fefct erleidtert frabe.

Reinen Seeren Recenfenten banfe ith auf bas verbindlid)ffe bafúr, baßj fie mid), burt) iţre grưnblichen BemerEungen nod) auf Mandes aufmerffam gemadt ḩaben, waz id bei ber er,

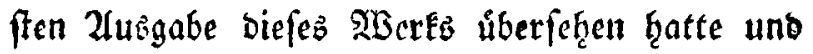
bemerfe nur nod): Daps idh, bei ber nodmaligen Bearbeitung ber Bief̧judft, nod) Mandjes hiie und ba berifftiget unb vervollftånbigt, aud bes

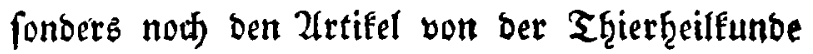

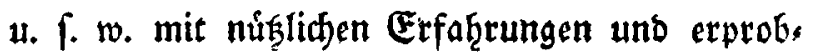

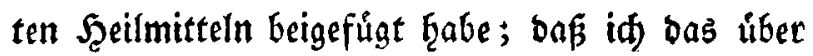

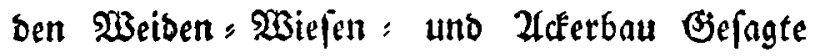
gånjlid) umarbeiten und biefe Stưcle fuftema. tiff unb in ifrem ganzen Uñfange beţandeln, folglid) aud bie tef̧re von ber Dreis uno ßiers Felber "Wirthfihaft, fo weit id foldje auf Ers

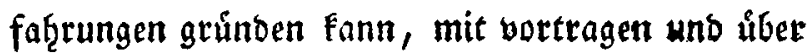
Den Nukzen ber englijajen $\mathfrak{Z}$ akerwerf jeuge, fo wie über bie 2 rt, wie man bie Bier "Felber , Wirth.

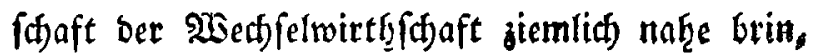
gen Eonne, bas Slotţige fagen werbe. 
Ueber ben britten $\mathfrak{T}$ heil ber erften Iubgabe

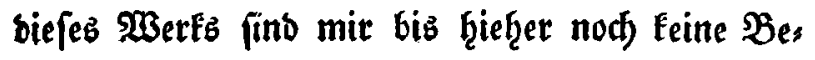

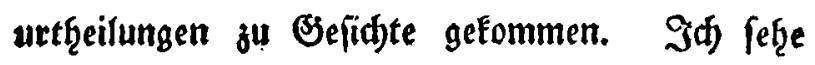
foldjen fef̧nlid) entgegen, um fie zu ber ßervolls fommnung beffelben benufzen ju fỏnnen.

Den hiier folgenben erften $\mathfrak{B}$ anb biefer neuen Zügabe empfeb̨le id) ben Şerrn Recenjenten jur genauen ’růfung unb unparthenifdgen Bes urthęeilung, bamit er in ben folgenben $\mathfrak{B a ̊ n} b e n$ allenfalls nod) verbollfănbigt uno baburd) befto meל̧r Nuşen geftiftet werben móge. 